\title{
Adequacy of operating reserves for power systems in future european wind power scenarios
}

Das, Kaushik; Litong-Palima, Marisciel; Maule, Petr; Sørensen, Poul Ejnar

Published in:

Proceedings of IEEE Power and Energy Society General Meeting 2015

Link to article, DOI:

10.1109/PESGM.2015.7286548

Publication date:

2015

Document Version

Peer reviewed version

Link back to DTU Orbit

Citation (APA):

Das, K., Litong-Palima, M., Maule, P., \& Sørensen, P. E. (2015). Adequacy of operating reserves for power systems in future european wind power scenarios. In Proceedings of IEEE Power and Energy Society General Meeting 2015 (pp. 1-5). IEEE. https://doi.org/10.1109/PESGM.2015.7286548

\section{General rights}

Copyright and moral rights for the publications made accessible in the public portal are retained by the authors and/or other copyright owners and it is a condition of accessing publications that users recognise and abide by the legal requirements associated with these rights.

- Users may download and print one copy of any publication from the public portal for the purpose of private study or research.

- You may not further distribute the material or use it for any profit-making activity or commercial gain

- You may freely distribute the URL identifying the publication in the public portal 


\title{
Adequacy of Operating Reserves for Power Systems in Future European Wind Power Scenarios
}

\author{
Kaushik Das*, Marisciel Litong-Palima, Petr Maule and Poul E. Sørensen \\ Department of Wind Energy \\ Technical University of Denmark \\ Ris $\emptyset$, Denmark \\ Email: *kdas@dtu.dk
}

\begin{abstract}
Wind power generation is expected to increase in Europe by large extent in future. This will increase variability and uncertainty in power systems. Imbalances caused due to uncertainty in wind power forecast can trigger frequency instability in the system. These imbalances are handled using operating reserves. To study the effects of these imbalances, anticipated wind scenarios for European power systems are modelled for 2020 and 2030. Wind power forecasts for different time scales and real-time available wind power are modelled. Based on these studies, this paper qualitatively analyzes the adequacy of primary and secondary reserves requirements for future European power systems. This paper also discusses the challenges due to the uncertainty in wind power forecasts and their possible solutions for wind installation scenarios for 2020 and 2030.
\end{abstract}

Index Terms-operating reserves, wind generation, ENTSO-E, forecast error, variability

\section{INTRODUCTION}

Power system should operate in a reliable and secured manner. In order to operate the system with stable frequency, the generation and load should always match. Since a power system has to deal with many uncertainties originating from variability of load, network topology, natural and technical disturbances, stochastic generations etc., there are always mismatches between consumptions and generations. These mismatches are met with operating reserves in order to prevent frequency instability [1]. Different types of operating reserves - both manual and automatic are used to handle these uncertainties. There are different nomenclatures for operating reserves. In Union for the Co-ordination of Transmission of Electricity (UCTE) operation handbook [2], different operating reserves were referred to as primary reserves, secondary reserves and tertiary reserves based on the type of control used to stabilize the frequency of the network. These reserves are referred as frequency containment reserves, frequency restoration reserves and replacement reserves based on their functionalities in recent European Network Transmission System Operator (ENTSO-E) Network Code on Load-Frequency Control and Reserves [3]. Whereas, operating reserves are classified as automatic active reserve (Frequency controlled normal operation reserve and Frequency controlled disturbance reserve), fast active disturbance reserve, slow active disturbance reserve and reactive reserve in Nordic Grid Code [4]. The conventions of primary reserve, secondary reserve and tertiary reserve are followed in this paper. Primary reserves are automatic reserves activated within seconds after the mismatches, whereas secondary reserves are activated in minutes range and tertiary reserves are for longer time frame from minutes to an hour. Primary reserve requirement for the system is generally determined according to n-1 security criterion of the system, which is typically the maximum generation/load that can get disconnected when any one of the power system equipment goes down (sometimes, referred as dimensioning fault). Secondary reserves are automatic reserves allotted to Automatic Generation Control (AGC) used to maintain the frequency of the control area as well as to control the tie-line power flow with neighboring control area to a pre-set value. Tertiary reserves are deployed manually which generally act as balancing reserves for longer time scales ranging from minutes to hours. Fig. 1 [2] explains the activation of different reserves as discussed above.

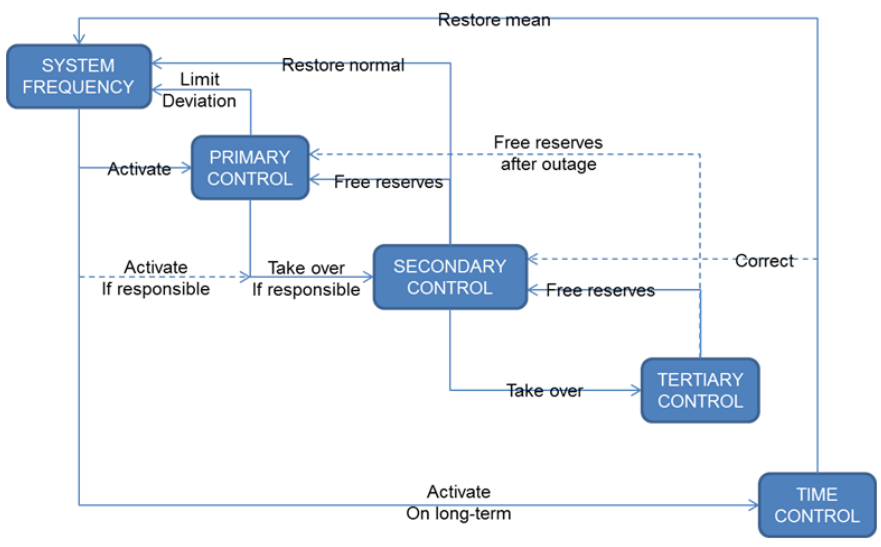

Fig. 1. Different types of reserve activation by different controls

With increasing penetration of wind power generation, uncertainties in the system also increases. Imbalance in wind power due to the variability of wind speed is mainly caused by error in wind forecast. The forecast error decreases as time horizon reaches closer to operation period. Therefore, the transmission system operators at the control center can take better decisions as it moves close to the real time operation in order to reduce the imbalance. The remaining imbalance 
will be handled by operating reserves in real-time. However, it is very important to note that the reserves utilized for this imbalance may reduce the reserve available to handle any contingency as per $\mathrm{n}-1$ security constraint.

In past, many studies have been performed regarding requirements of operating reserves with integration of wind power generation. Ela et. al. [5] and Milligan et. al. [6] gave comprehensive reviews of operating reserves with integration of variable generations. Ela et. al. [7] and Holttinen et. al. [8] discusses about determination of requirements of operating reserves with integration of wind power generation. Kiviluoma et. al. [9], Botterud et. al., [10] discuss impacts of wind power integration in operating reserve requirements from power system market and unit commitment point of view. Menemenlis et. al. [11] shows the advantages of using dynamic operating balancing reserve at time horizon of 1-48 hours over static reserves with integration of wind power.

This paper analyzes the requirement of short term operating reserves to handle the imbalance in the European power system for future wind power scenarios of 2020 and 2030 of ENTSO-E networks. This paper also tries to analyze whether this imbalance can be handled with slower secondary and tertiary reserves alone or the activation of primary reserve is imperative. This paper also investigates the requirement of dynamic automatic reserves as opposed to static reserves in future power systems with large penetration of wind power.

The structure of the paper is as following: Wind power predictions for different time horizons are done using software developed in Wind Energy Department at Technical University of Denmark, called CORWIND. Section II describes the details of CORWIND. Modelling of 2020 and 2030 wind generation scenarios are discussed in Section III. Analysis of the imbalances in the wind power based on wind power predictions and the real-time available wind power is also presented in Section III. Section IV describes the challenges and possible solutions for future wind power scenarios. Section $\mathrm{V}$ concludes the paper while providing motivations for future research in this field.

\section{CORWIND}

CORWIND is relevant to simulating the wind power output over a large area that features realistic fluctuations from time scales of a few seconds to a couple of hours [12], [13], [14]. The real-time wind power output is called the available wind power $P_{A V}$ in this study. CORWIND can also be used to estimate a wind power forecast $\left(P_{D A}\right.$ and $\left.P_{H A}\right)$ that corresponds to $P_{A V}$. Fig. 2 shows an overview of a general method used to simultaneously estimate the available wind power, the day-ahead and hour-ahead wind power forecasts.

The input to CORWIND is the wind speed from a meteorological model. Currently, the Weather Research and Forecasting (WRF) mesoscale model is used to provide the wind speed values at specified WRF grid points at an hourly resolution. CORWIND interpolates these values to the location of the points in this study. A wind speed value for an hour is used to estimate a power spectral density (PSD) that is relevant

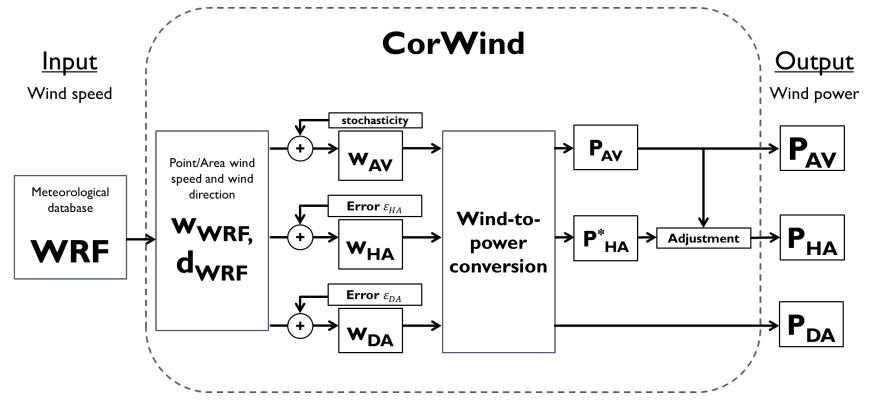

Fig. 2. CORWIND uses an estimate of the power spectral density (PSD) of the wind speed time series that is consistent with measured spectra.

to the hour. In order to account for the observed correlation between the wind speed values at two points, the PSD for all the points are prepared according to an empirical spectral coherence function. The coherent PSDs are then inverted to give the wind speed time series for each point. The wind power arising from a given wind speed condition is estimated using a wind-to-power conversion module. This gives the available power $P_{A V}$

The same wind speed values from WRF are used to generate a day-ahead wind speed forecast by adding an error term obtained from an autoregressive and moving average (ARMA) random process of horizon length of 12-36 time steps or hours. Similarly for $P_{A V}$, the corresponding wind power forecast is estimated by a wind-to-power conversion module.

The wind speed values from WRF are again used to generate hour-ahead wind speed forecast by adding an error term obtained from the same ARMA process, albeit at a shorter horizon length. When converted to power, this gives the hourahead wind power forecast $P_{H A}^{*}$. Basically, CORWIND uses an adjustment procedure that aligns the beginning part of the initial wind power forecast estimate $P_{H A}^{*}$ with the values of the available wind power $P_{A V}$ near the time of the update, to give the final hour-ahead wind power forecast $P_{H A}$. The method has been optimized using measurement and historical forecast data such that the differences between the $P_{D A}$ or $P_{H A}$ with $P_{A V}$ gives a realistic estimate of the day-ahead or hour-ahead wind power forecast error.

\section{Modelling AND Data Analysis of Future Wind SCENARIOS}

Anticipated wind power installation scenarios for ENTSOE networks for 2020 and 2030 are developed based on data from different sources [15],[16]. Scenarios are validated and adjusted according to EWEA report [17]. Table I shows the anticipated installed wind capacity in GW of ENTSO-E networks for 2020 and 2030. Fig. 3 shows the wind scenario of ENTSO-E networks UK, Continental Europe (CE), Baltic, Nordic and Ireland for 2020.

CORWIND is used to generate forecasted day ahead, hour ahead, online prognoses and real-time available power from the wind for each of the above-mentioned scenarios. These data are simulated for the wind data of 12 meteorological 
TABLE I

INSTALLED CAPACITY OF WIND GENERATION IN GW

\begin{tabular}{|c|c|c|c|c|}
\hline \multirow{2}{*}{ Network } & \multicolumn{2}{|c|}{2020} & \multicolumn{2}{c|}{2030} \\
\cline { 2 - 5 } & Onshore & Offshore & Onshore & Offshore \\
\hline UK & 12.515 & 9.146 & 19.149 & 31.935 \\
\hline CE & 164.912 & 24.976 & 214.486 & 93.899 \\
\hline Baltic & 0.591 & 0 & 0.558 & 4.855 \\
\hline Nordic & 9.214 & 8.769 & 12.817 & 27.685 \\
\hline Ireland & 3.635 & 2.485 & 5.102 & 3.470 \\
\hline Total & 190.868 & 45.377 & 252.114 & 161.845 \\
\hline
\end{tabular}

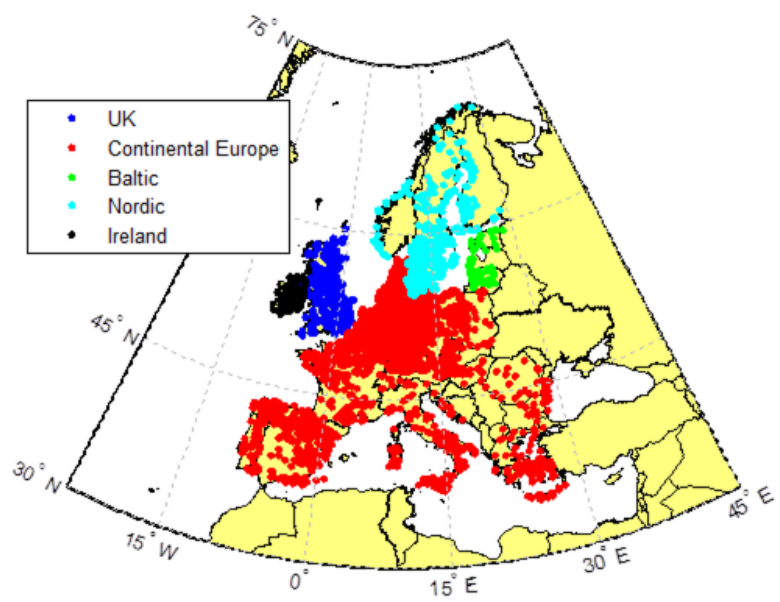

Fig. 3. Wind Generation Scenario for 2020

years. Online prognoses are obtained at the resolution of 5 minutes for 15 minutes. In this paper, results are mainly presented for 2020 scenario.

At the beginning of the hour, system is assumed to be balanced. The rationale behind this assumption is that all the generation and loads are balanced at the beginning of the hour through power trading. All the imbalances happening in the intra-hour operation are handled by slow, manual tertiary reserves as well as AGC based automatic secondary reserves. Therefore, intra-hour imbalance can be perceived as the difference between the real-time power and the hourahead prognosis. Since real-time power cannot be known in advance, accurate prediction of this imbalance is not possible. However, the accuracy of wind power forecast increases when it is close to the operation time. It can be observed from Fig. 4 that for a typical day, the curve of online prognosis is much closer to the real-time values whereas, hour-ahead prognoses are more erroneous. Therefore, operators can allocate and deploy tertiary reserves based on online prognosis. Since the activation and deployment time of tertiary reserve is quite slow (typically around $15 \mathrm{~min}$.), in the meantime the imbalance will be handled using secondary and primary reserves. Fig. 5 shows the power imbalance in UK network for 2020 scenario. It can be observed that the imbalance can be as high as +4.6 GW with installed capacity of around $21.65 \mathrm{GW}$. This imbalance is much higher as compared to $1800 \mathrm{MW}$ which is the overall primary reserve available in UK network. Although

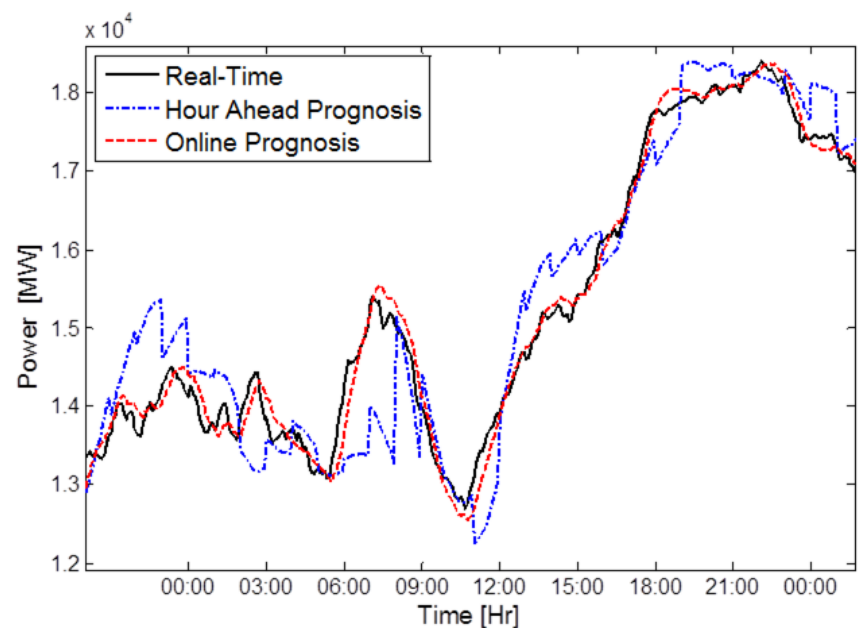

Fig. 4. Real-Time and Prognoses of Wind Power for a typical day

it is expected that most of this imbalance can be handled using tertiary reserves, but it is possible that the imbalance is too fast to activate tertiary reserves. In those cases, the imbalances need to be handled using primary and secondary reserves. The probability density function for the imbalance in UK for 2020 scenario is shown in Fig. 6. It can be observed that the tail beyond $1800 \mathrm{MW}$ of the density function is very long but probability values for these imbalances are too small. This signifies that if static reserves are dedicated to handle these imbalances, then most of the time the reserves beyond 1800 MW will remain unused. This might have economic implications. This advocates for a system in future where certain amount of reserves should be static (in this case 1800 MW) to handle imbalances of high probability whereas rest of the reserves should be allocated dynamically.

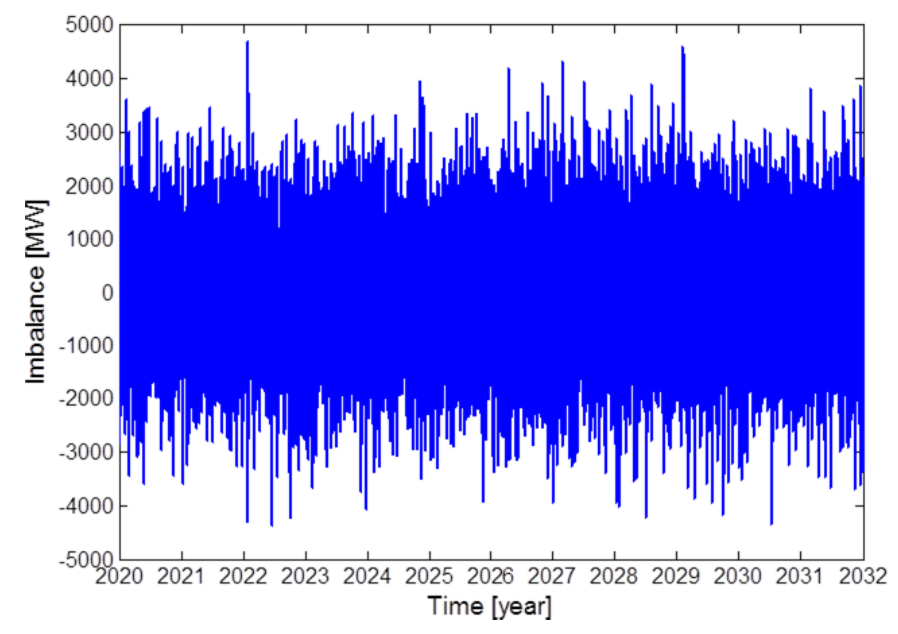

Fig. 5. Imbalance for UK in 2020 scenario

\section{Challenges and Solutions}

Error in hour-ahead prognoses can sometimes be as high as $100 \%$. In these situations, imbalances from the wind 


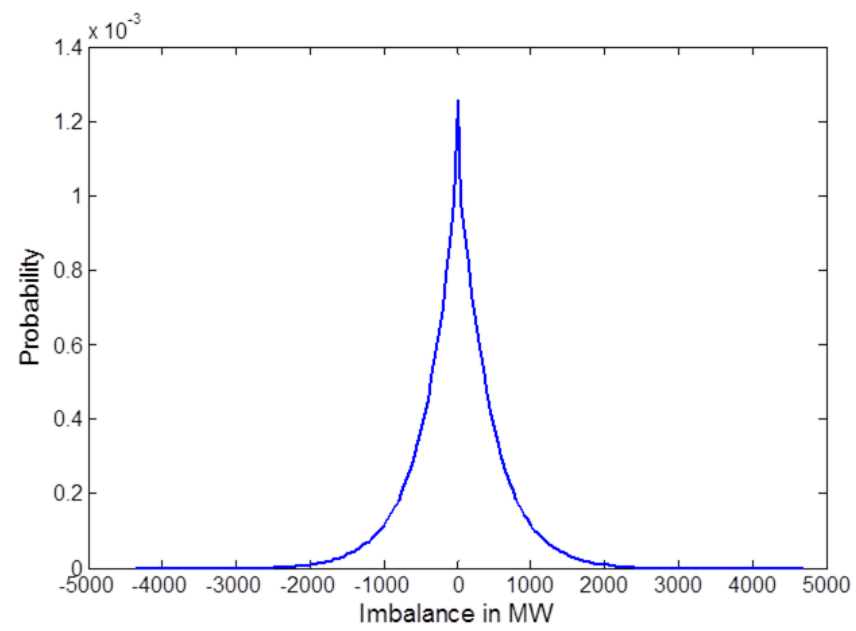

Fig. 6. Probability Density Function for the Imbalance in UK network for 2020 scenario

generation can be very high especially if the penetration of wind power is high. Since primary and secondary reserves are limited and tertiary reserve activation is a slow process, these imbalances can even invoke short term frequency instabilities. These phenomena can be observed in the Nordic network as shown in Fig. 7. It can be observed from Fig. 7 that imbalance is abnormally high at point $\mathrm{A}$. It is important to mention the imbalance balancing practice at this point. In Nordic network, the balance responsible parties (BRP) schedule generation and trade themselves to balance in the day-ahead market. They also trade balancing reserves in the intra-day market, 1 hour ahead of delivery. In the operational hour, balancing is performed by the TSOs through regulating reserves (tertiary reserves), and automatic secondary and primary reserves. Nordic TSOs have defined automatic reserves of 600MW for normal operation and about $1000 \mathrm{MW}$ to cover the dimensioning fault [18]. As shown in Fig. 8, which is zoom-in at point A along

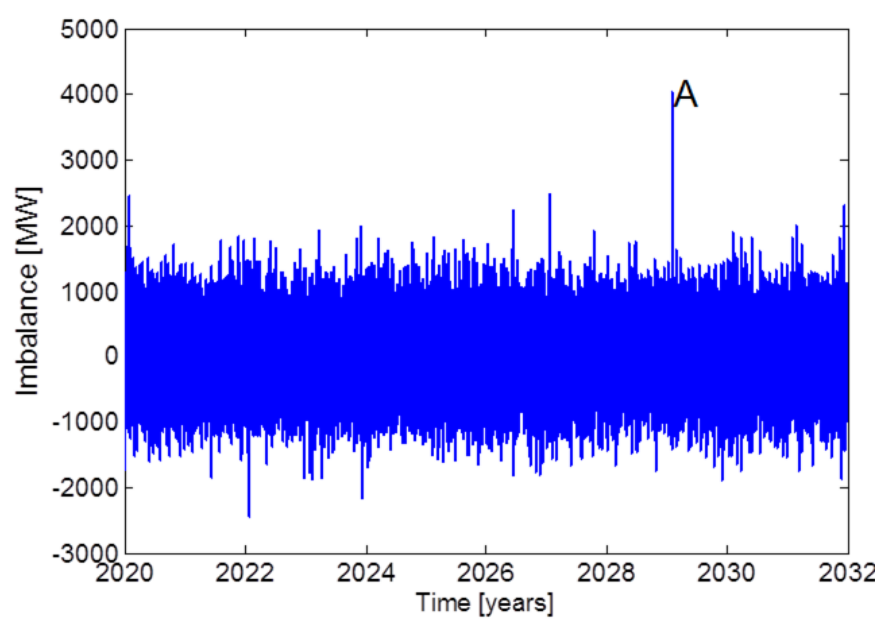

Fig. 7. Imbalance for Nordic Network in 2020 scenario

with real-time production values and online prognoses for
East Denmark (DK2), Sweden (SE) and Norway (NO), the errors are substantially high. Hour-ahead prognoses predicts high drop in generation (as storm is predicted) where wind speed is expected to grow beyond the cut-off speed shutting down the wind turbines. This phenomenon is observed over a large portion of the Nordic network. Although, it is observed that the real wind speed is not high enough to shut down the wind turbines, but just below the cut-off speed. As a result, the wind turbines kept generating to their peak capacity, which resulted in $100 \%$ error for quite high number of wind turbines. It is important to note that this phenomenon continued for exactly 6 hours where hour-ahead prognoses were not updated. The reason being the accuracy of the short term forecast like online prognosis or hour-ahead forecast is depended on the meteorological forecast. Meteorological forecast error is one of the main contributor to the wind power production forecast error. Meteorological forecast model are run every 6 hours in Nordic Networks as it is today [18]. This forecast error, therefore cannot be improved until new meteorological run occurs for the next 6 hours. The imbalance in this case is as high as 3500 MW for the Nordic network, whereas the available automatic reserves are much less for Nordic network as discussed previously. One solution to this problem is to update the meteorological forecast at higher frequency than 6 hours. This may be computationally challenging and expensive. Another solution can be simulation of short term forecasts in different way with lesser weighage to the meteorological forecasts, such as persistence forecasts. From the power system point of view, these types of situations can be handled with higher values of reserves. Since the probabilities of these situations are very low, allotting static reserves is neither an optimal nor an economical choice. Therefore, the values of probabilistic estimation of dynamic reserves for these kinds of situations could be evaluated. Fig. 9 shows

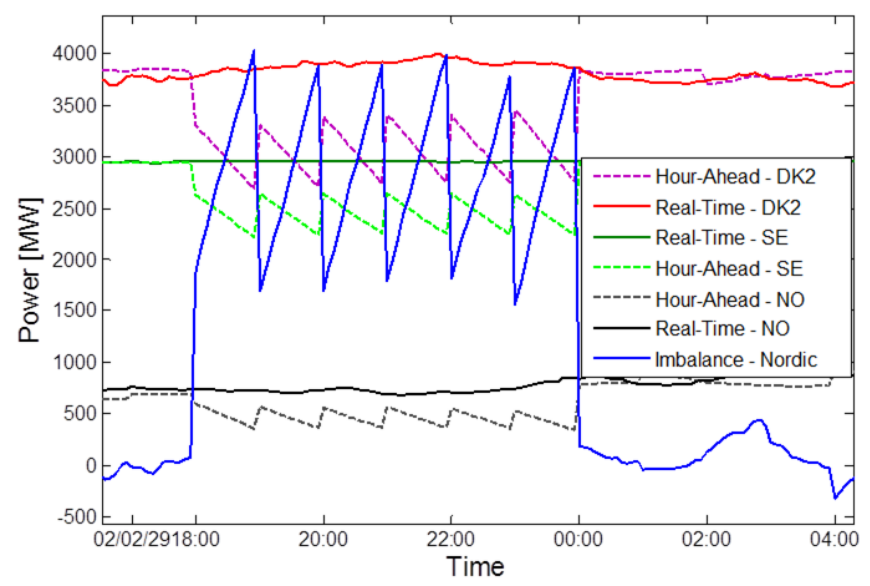

Fig. 8. Hour-Ahead Prognoses, Real-Time Values and Imbalance for Nordic Network in 2020 scenario

another interesting and challenging situation. Fig. 9 shows the imbalance in the UK network for a short period of 1 hour. It can be observed that the imbalances changes from 
347.9 MW at 6.55 to -1778 at 7.00 . This rate of change of imbalance is very high. Main reasons for this high rate of change are sudden change in hour ahead prognoses to follow meteorological forecasts. It is also important to mention that probability of occurrence of these situations is quite high. In situations like this, secondary reserve may not be fast enough to be deployed completely within 5 minutes, since generally secondary reserves are completely activated 30s after the imbalance until 15 minutes. Therefore, these types of situations will require utilizing of primary reserves in order to prevent frequency instability. One way to handle this challenge is by increasing the primary reserve. The required primary reserve will be additional to the system requirement to satisfy n-1 security constraint. Since the probabilities of these situations are high, the primary reserves allotted to handle these imbalances might add to static reserves and not to dynamic reserves. This increases the cost of primary reserve. Another solution could be faster secondary control support. Faster secondary control from AGC needs to be studied to find out the requirement of primary reserves to deal with this kind of imbalance. Secondary reserves are also limited. Therefore, the limits of secondary control reserves should also be increased if faster secondary control is envisaged to handle these imbalances.

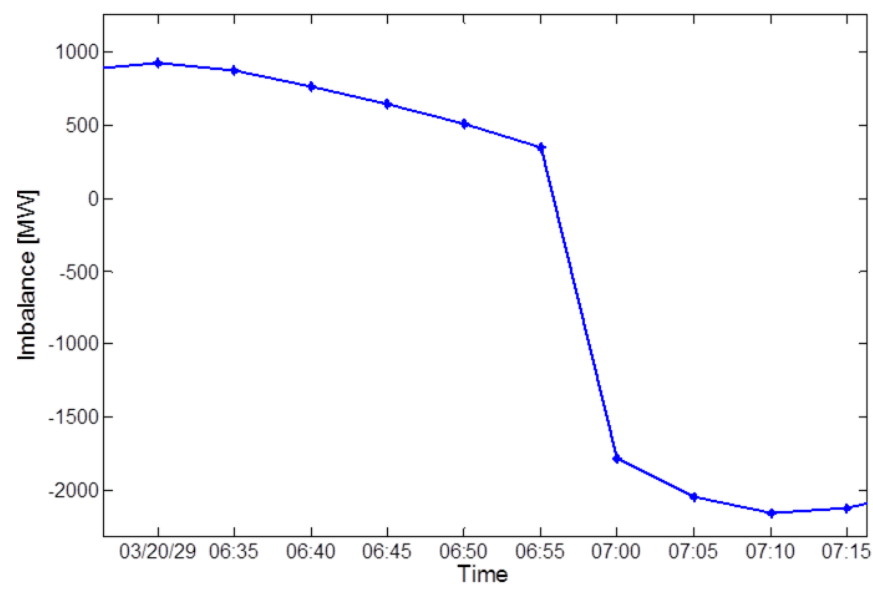

Fig. 9. Imbalance for 45 minutes in UK network for 2020 scenario

\section{CONCLUSION}

This paper shows that in future wind scenarios, imbalances arising due to forecast error can be high enough to invoke frequency instability. This urges the study for the adequacy of operating reserves in the future networks. Manual and slow tertiary reserves can reduce the imbalance substantially in the longer term. In order to model the tertiary control, a delay of 10-15 minutes should be considered. This delay corresponds to operator behavior, deployment and activation time of tertiary reserve sources etc. Remaining imbalances should be handled by faster, automatic primary and secondary reserves. A thorough study should be conducted to find out the amount of primary reserves required for different values and rates of secondary control reserves.

\section{ACKNOWLEDGMENT}

The research leading to these results has received funding from the European Union Seventh Framework Programme (FP7/2007-2013) under grant agreement no. 283012.

\section{REFERENCES}

[1] P. Kundur et al., "Definition and classification of power system stability," IEEE Transactions on Power Systems, vol. 19, no. 3, pp. 1387-1401, Aug. 2004.

[2] UCTE, "Operation Handbook," union for the co-ordination of transmission of electricity, Tech. Rep., June 2004.

[3] ENTSO-E, "Network Code on Load Frequency Control and Reserves (LFCR)." [Online]. Available: https://www.entsoe.eu/major-projects/network-code-development/ load-frequency-control-reserves/Pages/default.aspx

[4] Nordel, "Nordic Grid Code (Nordic collection of rules)," $2007 . \quad$ [Online]. Available: https://www.entsoe.eu/fileadmin/user_upload/_library/publications/ nordic/planning/070115_entsoe_nordic_NordicGridCode.pdf

[5] E. Ela, M. Milligan, and B. Kirby, "Operating Reserves and Variable Generation,” NREL/TP-5500-51928, August 2011.

[6] M. Milligan et al., "Operating Reserves and Wind Power Integration:An International Comparison," in Proceedings of 9th International Workshop on Large-Scale Integration of Wind Power into Power Systems, Oct 2010.

[7] E. Ela, B. Kirby, E. Lannoye, M. Milligan, D. Flynn, B. Zavadil, and M. OMalley, "Evolution of Operating Reserve Determination in Wind Power Integration Studies," in Proceedings of IEEE PES General Meeting, July 2010.

[8] H. Holttinen et al., "Methodologies to Determine Operating Reserves due to Increased Wind Power," IEEE Transactions on Sustainable Energy, vol. 3, no. 4, pp. 713-723, 2007.

[9] J. Kiviluoma, M. O’Malley, A. Tuohy, P. Meibom, M. Milligan, B. Lange, H. Holttinen, and M. Gibescu, "Impact of wind power on the unit commitment, operating reserves, and market design," in Proceedings of IEEE PES General Meeting, July 2011, pp. 1-8.

[10] A. Botterud, Z. Zhou, J. Wang, J. Valenzuela, J. Sumaili, R. J. Bessa, H. Keko, and V. Miranda, "Unit commitment and operating reserves with probabilistic wind power forecasts," in Proceedings of IEEE PowerTech, Trondheim, 2011.

[11] N. Menemenlis, M. Huneault, and A. Robitaille, "Computation of Dynamic Operating Balancing Reserve for Wind Power Integration for the Time-Horizon 148 Hours," IEEE Transactions on Sustainable Energy, vol. 3, no. 4, pp. 692-702, 2012.

[12] P. Sørensen, N. A. Cutululis, A. Vigueras-Rodriguez, L. E. Jensen, J. Hjerrild, M. H. Donovan, and H. Madsen, "Power Fluctuations From Large Wind Farms," IEEE Transactions on Power Systems, vol. 22, pp. 958-965, 2007.

[13] P. Sørensen, P. Pinson, N. A. Cutululis, H. Madsen, L. E. Jensen, J. Hjerrild, M. H. Donovan, and A. Vigueras-Rodrguez, "Power fluctuation from large offshore wind farms Final report," Ris, Tech. Rep., 2009.

[14] P. Sørensen and N. A. Cutululis, "Wind farms' spatial distribution effect on power system reserves requirements," in IEEE International Symposium on Industrial Electronics (ISIE), 2010, pp. 2505-2510.

[15] 4COffshore, "Global Offshore Wind Database." [Online]. Available: http://www.4coffshore.com/windfarms/

[16] TheWindPower, "Wind Farms List." [Online]. Available: http://www. thewindpower.net/windfarms_list_en.php

[17] EWEA, "Pure Power," 2011. [Online]. Available: http://www.ewea.org/fileadmin/ewea_documents/documents/ publications/reports/Pure_Power_III.pdf

[18] ENTSO-E, "Impact of increased amounts of renewable energy on Nordic power system operation," 2010. [Online]. Available: https://www.energinet.dk/SiteCollectionDocuments/ Engelske\%20dokumenter/El/Wind\%20report.pdf 